[Highlight]

\title{
顺式烯二炔的表面选择性合成
}

\author{
吴 凯 \\ (北京大学化学与分子工程学院, 北京 100871)
}

\section{Selective Synthesis of cis-Enediyne on Surface}

WU Kai

( College of Chemistry and Molecular Engineering of Peking University, Beijing, 100871, P. R. China)

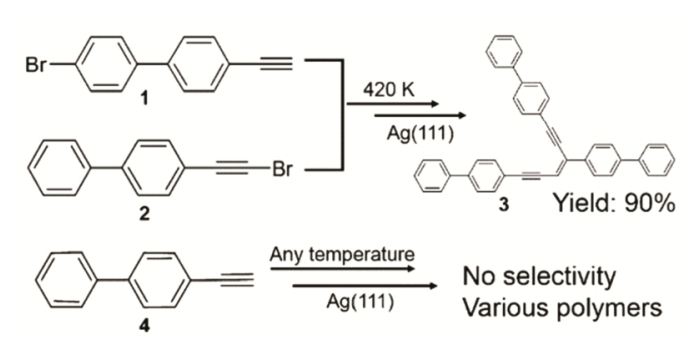

自上世纪八十年代以来, 顺式烯二炔型化合 物因其具备抗癌药物作用而存在巨大的潜在应用 价值, 吸引了有机合成领域的广泛关注和研究 ${ }^{1,2}$ 。 然而, 由于炔烃具有众多的反应路径, 传统的溶 液有机反应通常难以实现对顺式烯二炔的高选择 性合成, 而且不可避免地需要利用多种复杂的反 应物和催化剂。即便在近年来借助扫描隧道显微 镜(STM)等研究而迅速发展的表面合成领域, 调控 顺式烯二炔这类多聚非对称性产物的反应路径依 然是一大挑战。目前为止, 二维表面限域方法也 仅仅实现了对具备热稳定性的二聚物或高对称性 物种的合成调控 ${ }^{3}$, 对结构更复杂且热稳定性不足 的产物合成尚未见报道。

最近中国科学技术大学朱俊发教授课题组与 武晓君教授课题组合作, 首次在 $\operatorname{Ag}(111)$ 表面选择 性地合成了顺式烯二炔型化合物, 相关结果发表 在 Angewandte Chemie International Edition 杂志 上 ${ }^{4}$ 。为了解决在金属表面顺式烯二炔形成之后容 易进一步发生取代或加成反应的问题, 他们提出 了一种独特的氢键保护机制。通过在末端炔烃类 前驱体分子上引入溴取代基, 在反应过程中随着
$\mathrm{C}-\mathrm{Br}$ 键的断裂, 表面吸附的溴原子通过溴氢卤 键的作用, 使反应生成的顺式烯二炔化合物聚集 成有序的密堆岛屿。这些密堆岛屿对顺式烯二炔 的进一步加成或取代反应带来了强大的空间位阻, 从而使炔烃反应停留在这一步, 因此得到了高产 率的顺式烯二炔。

研究人员为了进一步验证该调制机理, 做了 一系列的对比实验和基于密度泛函理论(DFT)的 反应能垒计算。结果显示, 没有卤素取代基的前 驱体分子发生表面聚合反应之后, 并未出现任何 一种炔基多聚物的高选择性, 这是因为缺乏卤氢 键的作用, 反应产物无法有效聚集成密堆岛屿; DFT 计算同样揭示了密堆岛屿对提高顺式烯二炔 加成反应的能垒具有非常显著的效果。同时, 他 们通过其他一些控制实验研究了这种特殊的保护 机制的强度和稳定性: 在更高温度 $520 \mathrm{~K}$ 的 $\mathrm{Ag}(111)$ 单晶表面, 密堆岛屿的保护机制会被打破, 致使 顺式烯二炔的产率明显下降; 在低浓度的情况下, 更小的有序密堆岛屿会让顺式烯二炔的进一步反 应变得容易, 也造成其产率的降低。

这一研究成果不仅提供了一条合成顺式烯二 
炔型化合物的新方法, 而且更重要的是, 文中提 出的利用产物分子间的氢键作用保护产物的独特 机制, 势必对以后的表面合成领域带来全新的启 示。

\section{References}

(1) Jones, G. B.; Wright, J. M.; Plourde, G. W.; Hynd, G.; Huber, R. S.; Mathews, J. E. J. Am. Chem. Soc. 2000, 122, 1937. doi: $10.1021 /$ ja993766b

(2) Basak, A.; Mandal, S.; Bag, S. S. Chem. Rev. 2003, 103, 4077. doi: $10.1021 / \mathrm{cr} 020069 \mathrm{k}$

(3) Klappenberger, F.; Zhang, Y. Q.; Bjork, J.; Klyatskaya, S.; Ruben M.; Barth, J. V. Acc. Chem. Res. 2015, 48, 2140. doi: $10.1021 / \mathrm{ja} 00222 \mathrm{a} 077$

(4) Wang, T.; Lv, H. F.; Fan, Q. T.; Feng, L.; Wu, X. J.; Zhu, J. F. Angew. Chem. Int. Ed. 2017, doi: 10.1002/anie.201701142 